
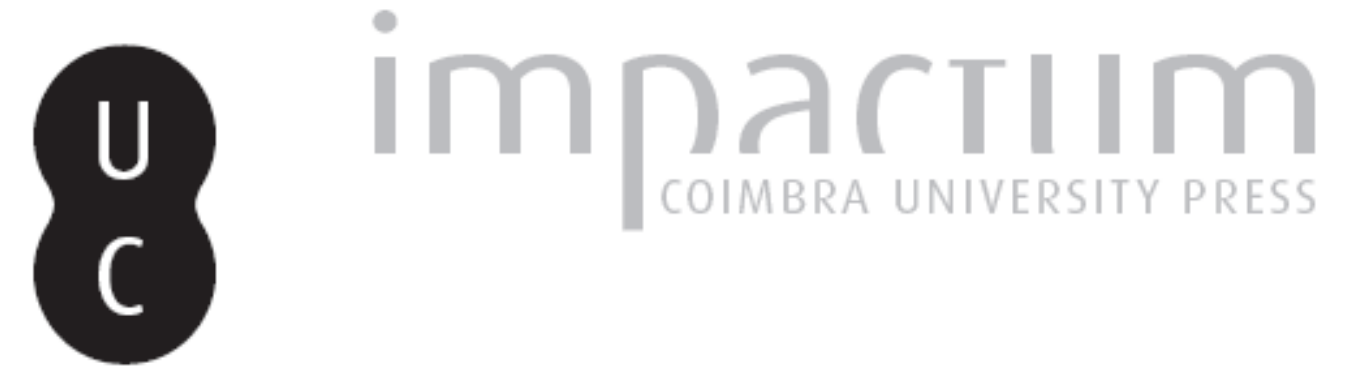

\title{
Órgãos de tubos da Igreja de Nossa Senhora do Loreto da nação italiana: instrumentos, organeiros e afinadores em contexto com a arte da organaria em Portugal (séculos XVI-XXI)
}

\author{
Autor(es): $\quad$ Tudela, Ana Paula
}

Publicado por: Imprensa da Universidade de Coimbra

URL

persistente:

URI:http://hdl.handle.net/10316.2/45640

DOI:

DOI:https://doi.org/10.14195/0870-8584_13_7

Accessed : $\quad$ 26-Apr-2023 03:28:39

A navegação consulta e descarregamento dos títulos inseridos nas Bibliotecas Digitais UC Digitalis, UC Pombalina e UC Impactum, pressupõem a aceitação plena e sem reservas dos Termos e Condições de Uso destas Bibliotecas Digitais, disponíveis em https://digitalis.uc.pt/pt-pt/termos.

Conforme exposto nos referidos Termos e Condições de Uso, o descarregamento de títulos de acesso restrito requer uma licença válida de autorização devendo o utilizador aceder ao(s) documento(s) a partir de um endereço de IP da instituição detentora da supramencionada licença.

Ao utilizador é apenas permitido o descarregamento para uso pessoal, pelo que o emprego do(s) título(s) descarregado(s) para outro fim, designadamente comercial, carece de autorização do respetivo autor ou editor da obra.

Na medida em que todas as obras da UC Digitalis se encontram protegidas pelo Código do Direito de Autor e Direitos Conexos e demais legislação aplicável, toda a cópia, parcial ou total, deste documento, nos casos em que é legalmente admitida, deverá conter ou fazer-se acompanhar por este aviso.

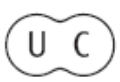




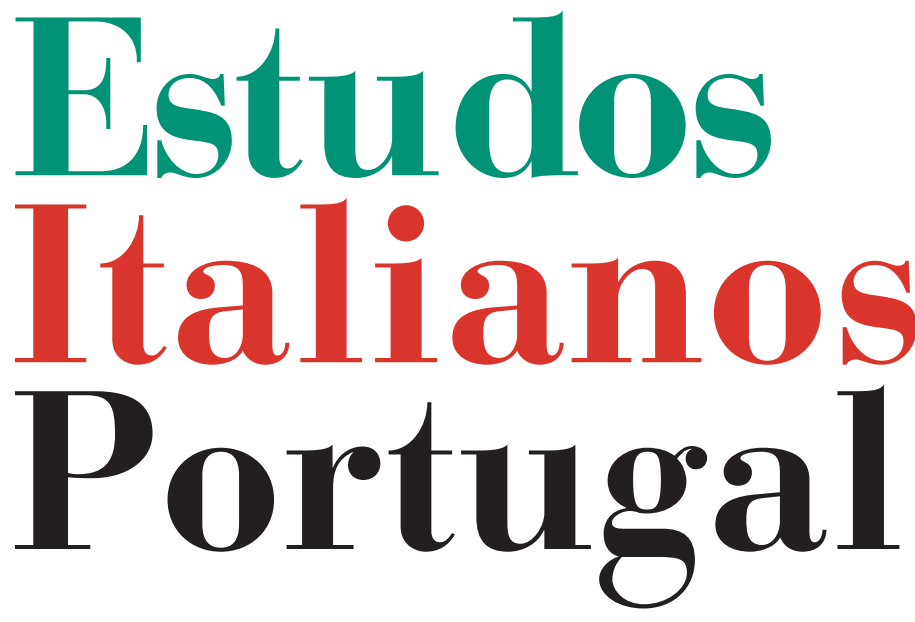

Instituto

Italiano

de Cultura

de Lisboa

Nova Série

$\mathrm{N}^{\mathbf{0}} 13$

2018 


\author{
ÓRGÃO DE TUBOS DA IGREJA \\ DE NOSSA SENHORA DO LORETO \\ DA NAÇÃO ITALIANA: \\ INSTRUMENTOS, ORGANEIROS E AFINADORES \\ EM CONTEXTO COM A ARTE DA ORGANARIA \\ EM PORTUGAL (SÉCULOS XVI-XXI)
}

Ana Paula Tudela*

O TEXTO segue uma ordem cronológica e no intuito de conferir uma maior inteligibilidade ao tema, a cronologia foi dividida em períodos que iniciam com as renovações arquitectónicas da Igreja de Nossa Senhora do Loreto de Lisboa. A excepção vai para o reinado de D. João V (1707-1750), durante o qual o templo não sofre reconstrução alguma mas assiste-se a um incremento no requinte decorativo para o qual temos provas da encomenda de um órgão.

Para os momentos em que não temos provas mas consideramos a possibilidade de terem sido encomendados novos instrumentos, optámos por apresentar hipóteses tendo em conta o contexto das escolhas locais na época e o padrão das escolhas italianas nos períodos documentados.

A partir de finais do século XVIII tomámos como fio condutor o órgão histórico que se encontra no coro alto. Este instrumento é um testemunho da técnica portuguesa de construção desse período mas também das diversas reparações e alterações dos séculos XIX e XX, tornando-se assim

* Investigadora na U.A.L. de 1997 a 2003 e no Museu da Música de 2000 a 2002. Independente de 2003 a esta parte, biografa construtores de instrumentos musicais de diversas especialidades. É responsável pelos arquivos históricos da Basílica dos Mártires.anapaula.tudela@gmail.com 
num repositório das diversas opções dos artífices especializados em consertos e mais tarde em restauros.

\section{8-1580: DA FUNDAÇÃO À 1. ${ }^{\mathrm{a}}$ RECONSTRUÇÃO}

A Igreja do Loreto da Nação Italiana, autorizada por bula de 1518, começa o seu percurso na era da grande cisão da igreja romana, com o movimento reformista de Martinho Lutero (1483-1546), o protestantismo. A igreja de Roma reagiu com medidas contra-reformistas firmadas no concílio de Trento (1545-1563). O plano incluía reformas burocráticas, urbanísticas, do conhecimento em geral, mas, sobretudo, artísticas. As artes, entendidas como veículos importantes de comunicação e transmissão doutrinal, foram largamente contempladas na contra-reforma. A música em particular, como a mais importante pela sua intensidade, universalidade, um poderoso veículo na propagação da fé. Nesse contexto, o órgão de tubos foi-se tornando um elemento indispensável na dignidade da celebração litúrgica e na comunicação com os fiéis.

A primeira grande ampliação da Igreja do Loreto dá-se precisamente no rescaldo do Concílio. A campanha de obras que decorreu entre 1575 e 1580 terá sido, com certeza, acompanhada de uma primorosa guarnição artística do templo. A aquisição de um órgão de tubos de qualidade nesta grande remodelação é quase uma certeza.

Desta época não sobreviveram documentos do cartório da igreja, mas podemos tentar reflectir tendo em conta o contexto religioso e a informação disponível sobre a organaria e a presença de órgãos nos templos do reino português.

Para o século XVI, é extensa a documentação por explorar sobre a aquisição, construção e manutenção de órgãos, quer em solo português quer nos domínios portugueses de alémmar. A título de exemplo, deixamos aqui alguns casos contemporâneos da fundação da Igreja do Loreto, que ilustram a 
presença deste instrumento por todo o território português: Goa $^{1}$, Malaca ${ }^{2}$, Alcobaça ${ }^{3}$, Évora ${ }^{4}$ Castelo de Vide ${ }^{5}$ e Niza ${ }^{6}$. Apesar da falta de estudos aprofundados neste domínio, temos os nomes de diversos organeiros deste período: António de Mesquita, organeiro do rei ${ }^{7}$, Bento Solorzano, Heitor Lobo, Elias de Lemos, António Rombo, Alonso de Cresmonte (espanhol) ${ }^{8}$, Afonso Lopes, Lopo Gonçalves, Pedro Dias $^{9}$, Diogo de Aranda ${ }^{10}$ e mestre João ${ }^{11}$.

${ }^{1}$ Arquivo Nacional Torre do Tombo (ANTT), Corpo Cronológico, Parte II, mç. 80, n. ${ }^{\circ} 158$ (pagamento de 2.000 réis a Pedro Dias por consertar os órgãos de Goa, Igreja de S. Francisco, 1519/03/20).

${ }^{2}$ ANTT, Corpo Cronológico, Parte I, mç. 24, n. ${ }^{\circ} 44$ (órgãos para levar à Igreja de Malaca, 1519/03/20).

${ }^{3}$ ANTT, Corpo Cronológico, Parte II, mç. 83, n.o 36 (pedido de carpinteiros para consertar os órgãos, 1519/07/12).

${ }^{4}$ ANTT, Corpo Cronológico, Parte III, mç. 8, n.o 27: "Ordem do cabido da sé de Évora, em que manda ao recebedor das rendas da dita sé pague a Afonso Lopes 1.600 réis de seu trabalho nos órgãos", 1522/09/05.

${ }^{5}$ ANTT, Chancelaria de D. Manuel I, liv. 10, fl. 39 (órgãos da Igreja da Vila e da Misericórdia, 1517/05/22).

${ }^{6}$ ANTT, Corpo Cronológico, Parte II, mç. 82, n. ${ }^{o} 22$ (pagamento de 1.800 réis a Alonso de Cresmonte, organista castelhano, por afinar os órgãos da igreja da vila, 1519/05/24).

${ }^{7}$ Arquivo Distrital de Évora (ADEVR), Registo Notarial de Évora, Tabelião Pero Borges, lv. 302, fl. 123 (encomenda de órgão para o Convento dos Lóios, em Évora, 1590/07/07). Transcrição enviada pela Dr. a Antónia Conde, grupo de investigação de Cástris (Universidade de Évora).

${ }^{8}$ Estes cinco organeiros são divulgados na obra de Michel'angelo Lambertini, Industria Instrumental Portugueza (Apontamentos), Lisboa, Typ. do Annuario Commercial, 1914, p. [5]. Lambertini informa na introdução que estes nomes foram revelados em artigos publicados na revista A Arte Musical por Sousa Viterbo (1845-1910).

${ }^{9}$ Estes três mestres são referidos nos documentos dos casos de Évora, Castelo de Vide e Goa, que cito nas notas 2, 5 e 6.

${ }^{10}$ ANTT, Corpo Cronológico, Parte I, mç. 97, n.o 97 (1556/03/05).

${ }^{11}$ ANTT, Corpo Cronológico, Parte I, mç. 93, n. ${ }^{\circ} 16$ (1554/07/18). Este organeiro é citado na obra de João de Freitas, História da Música Portuguesa, 2. ${ }^{a}$ Ed., Lisboa, Publ. Europa-América, 1995, p. 120, que por sua vez cita a obra de Joaquim de Vasconcelos, El rei D. João IV, Porto, 1900, mas nenhum refere a fonte documental. Mestre João, provavelmente de origem alemã, esteve activo no reinado de D. João III e os pagamentos pelo seu trabalho são ordenados pela rainha D. Catarina, natural da Áustria. 
Neste século é possível que tenham existido encomendas, podemos supor pelo menos uma. Embora possam ter feito recurso do aluguer até à grande reconstrução de 1575-1580, para a inauguração a 4 de Abril de 1580 é quase certo que terão encomendado um órgão.

Tomando como padrão as escolhas futuras da comunidade italiana, levantamos aqui três hipóteses para a $1 .{ }^{\mathrm{a}}$ metade do séc. XVI: a nível local, mestre João, organeiro da casa real e Heitor Lobo, que construiu para o Mosteiro de Santa Cruz de Coimbra ou encomenda a Itália, à oficina dos Antegnati. Para a 2. ${ }^{\text {a }}$ metade do séc. XVI: localmente a António de Mesquita, organeiro do rei ou em Itália a Cristoforo Valvasori. Antegnati e Valvasori terão sido os melhores organeiros italianos deste período ${ }^{12}$.

\section{1-1676: 2. ${ }^{a}$ RECONSTRUÇÃO}

Entre a recuperação do saque de 1580 e o incêndio de 1651, terá voltado a haver recurso ao aluguer de órgãos e provavelmente foram feitas novas encomendas. Vejamos quem eram os construtores portugueses ou a trabalhar em Portugal nesta época.

Durante o reinado dos Filipes (1580 e 1640) a corte tinha sido transferida para Madrid, que passou a ser o centro catalisador das artes. Este foi um período sobre o qual a tradição oral e as fontes bibliográficas em geral nos transmitem a ideia de termos vivido no território português um declínio das artes e ofícios. É certo que no domínio da organaria, aliás como no domínio da maioria das artes e ofícios deste período, os estudos estão por fazer, portanto, a percepção que temos hoje pode vir a ser alterada.

Em contracorrente, frei Nicolau de Oliveira, no "Livro das Grandezas de Lisboa" publicado em 1620, a fl. 97, regista a

${ }^{12}$ Michel'angelo Lambertini. "O Orgão”, id, A Arte Musical, Ano II, 30, Lisboa, Typ. do Annuario Comercial, 1900, p. 41. 
existência de cinco mestres que fazem órgãos. A confirmar-se este número, há ainda a apurar se eram oficiais continuadores de oficinas locais ou espanhóis, alemães ou outros, a residir em Lisboa.

Voltando à nossa fonte de referência, Lambertini regista para todo o século XVII apenas um organeiro na Industria Instrumental Portugueza, o alemão mestre Jorge que morava ao Carmo. A sua fonte é novamente um artigo de Sousa Viterbo que o localizou no papel de testemunha de um testamento redigido em $1620^{13}$. Viterbo refere também neste artigo a encomenda do bispo do Funchal para a Sé, no primeiro quartel do séc. XVII, a um organeiro de Córdova, de nome João Manuel.

No actual inventário dos órgãos históricos da região norte estão registados dois organeiros para este período: Michel Hensbergh, oriundo dos países baixos, órgão da Igreja do Bom Jesus, em Matosinhos, datado de 1685-1686 e Geraldo Vieira Porto, órgão da Sé de Miranda do Douro, datado de $1696^{14}$.

Em fontes ainda não exploradas pelos estudos neste domínio, para Lisboa temos a referência de um organeiro em 1654 que julgamos ser português: António Machado Pereira, mestre de fazer órgãos morador na cidade de Lisboa junto aos paços do marquês de Gouveia, a São João da Praça ${ }^{15}$. Para o resto do território português europeu, temos duas referências relativas à Igreja Matriz de Viana do Castelo: Tomé da Costa,

${ }^{13}$ Sousa Viterbo, "Curiosidades musicaes - LXV - Seis fabricantes de orgãos Mestre Jorge, Damião Luiz, Calixto de Barros Pereira, João Manuel, Alonso de Cresmonte e Bento de Soolorzano", Michel'angelo Lambertini, A Arte Musical, Ano XII, 280, 15/Ago, Lisboa, Typ. Pinheiro, 1910, p. 169.

${ }^{14}$ Inventário dos Órgãos Históricos da Região Norte / Projecto da Acer. http:// www.orgaos.acer-pt.org/ (consultado em 2 de Maio de 2018).

${ }^{15}$ ADEVR, Registo Notarial de Évora, Tabeliāo (?), Livro 823, fls. 93-94v. (encomenda de órgão para o convento de São Domingos, em Évora, 1654/10/). Transcrição enviada pela Dr. ${ }^{a}$ Antónia Conde, grupo de investigação de Cástris (Universidade de Évora). 
organeiro que fez um órgão em 1620 e Sebastião Fernandes, mestre organeiro que em 1638 fez a obra do órgão ${ }^{16}$.

Em síntese, do que já se conseguiu apurar, em Lisboa temos mestre Jorge, alemão, morador ao Carmo, nas imediações da Igreja do Loreto e António Machado Pereira, morador em São João da Praça, em Alfama. No norte do país temos a família Hensberg (ou Hemberg) dos países baixos e Geraldo Vieira, Tomé da Costa e Sebastião Fernandes. Para o sul não temos nomes mas sabemos que contrataram com o organeiro de Lisboa António Machado Pereira.

Esta primeira vaga de organeiros oriundos da Europa centro/norte, que a esta altura tinham atingido uma boa evolução técnica, parece ter sido bem acolhida pela comunidade italiana em Lisboa porque no seu arquivo ainda se conserva o recibo datado de 1691 , do pagamento pelo conserto do órgão, feito a Jan Ferdinando, quase de certeza oriundo dos países baixos. Deste primeiro testemunho documental do arquivo da Igreja do Loreto sobre um órgão retiramos dois elementos importantes: que a igreja nesta data tinha órgão próprio (não alugava) e juntamos mais um nome à lista dos organeiros activos em Portugal no século XVII - Jan Ferdinando.

\section{8-1749: REINADO DE D. JOÃO V}

Este período foi marcado por uma forte presença de músicos italianos na capela real portuguesa e, em consequência, na igreja da nação italiana. As relações sociais e profissionais destes músicos com as terras de origem deve ter favorecido os contactos com os melhores artífices da península itálica e afastou a contratação de alemães e flamengos pela igreja.

\footnotetext{
${ }^{16}$ Os dados destes dois organeiros foram recolhidos na base online do CEPESE (Centro de Estudos da População, Economia e Sociedade)

http://www.cepese.pt/portal/pt/bases-de-dados/artistas/res_obra_fulltext (consulta efectuada em 2 de Maio de 2018 usando o descritor “organeiro").
} 
No primeiro quartel do século XVIII reside e trabalha em Lisboa Johann Heinrich Hullenkampf, organeiro hamburguês, discípulo de Arp Schnitger. Porém, a escolha dos italianos do Loreto para afinações e pequenas reparaçōes recai sobre Pedro Nunes Silva ${ }^{17}$, afinador dos órgãos da capela real $^{18} \mathrm{e}$ a encomenda de um grande órgão fazem-na em Itália, a Filippo Testa, organeiro romano (fig. 1).

As caixas com as partes do órgão de Testa chegam a Lisboa em 1725. O órgão foi feito em Roma, despachado para Génova e dali para Lisboa. A ornamentação da caixa terá sido feita em Lisboa porque o entalhador Francesco Realdino Romano assina os recibos e data-os localizando-se em Lisboa Oriental ${ }^{19}$.

Esta encomenda da Igreja do Loreto a Filippo Testa, organeiro romano, é uma pista interessante a explorar na história dos órgãos da Basílica de Mafra. Para a sagração do templo, em 22 de Outubro de 1730, D. João V manda fazer seis órgãos: três no reino e três em Roma ${ }^{20}$. Até este momento desconhecemos as identidades quer do organeiro local quer do organeiro de Roma.

Ainda no reinado de D. João V, em 1741, o órgão da igreja, que tudo indica continua a ser o instrumento construído por Testa, é reparado por outro italiano que se encontrava de passagem em Lisboa, antes de rumar a Évora onde se estabeleceu: o genovês Pasquale Caetano Oldovino (c. 17201785) $)^{21}$ (fig. 2).

${ }^{17}$ Arquivo da Igreja de Nossa Senhora do Loreto de Lisboa (ANSL), Caixa IV, Maço 2, doc. 40 (n. ${ }^{\text {os. }}$ 1-6).

${ }_{18}$ ANTT, Registo Geral de Mercês, D. Pedro II, Livro 15, fl. 191 (PT-TTRGM/03/23090). Sucedeu no lugar a Francisco de Santo António, em 1703, ainda no reinado de D. Pedro II.

${ }^{19}$ ANSL, Masso cartão II, F, docs. 21-22 (1727/01/04).

${ }^{20}$ Biblioteca Nacional de Portugal (BNP) (Reservados), cartas de José Correia de Abreu, Caixa 41, N.o 7 (1729/07/27).

${ }^{21}$ ANSL, Masso X, fasc. 1, doc. 44 (1741/10/05). 
Estes instrumentos precisavam de pequenas reparações e manutenção com frequência. Em 1744 e 1745 aparecem mais despesas com reparações do órgão, realizadas pelo oficial Santos de Brito, recomendado pelo violinista da capela real Pedro Jorge Avondano (c. 1690-dep. 1748). No recibo não está especificada a especialidade deste oficial, cujo nome nos era desconhecido até agora. Poderá ser oficial organeiro mas também poderá ser um carpinteiro. Santos de Brito trabalhou 40 dias no órgão ${ }^{22}$.

\section{5-1785: 3. a RECONSTRUÇÃO}

No Grande Terramoto de 1755 o templo ficou muito destruído e o órgão de tubos ardeu. A campanha das obras de reconstrução durou 30 anos. No arquivo está guardado um documento datado de 1768 que indica a existência de um órgão novo em fase de construção ${ }^{23}$, mas não é referido por quem.

Vejamos quem eram os organeiros com oficina em Lisboa nesta altura: a oficina Cunha, agora sob a direcção de João da Cunha (1712-1762) e depois da viúva Cunha até 1774; a oficina dos organeiros Fontanes, nesta altura sob a direcção de Bento Fontanes (1742-1793) e Pedro António Boni (c. 1700-1774), natural da província de Laquila, Reino de Nápoles, que está em Lisboa, pelo menos desde 1757, a apresentar uma proposta à Patriarcal para um novo órgão.

Este organeiro napolitano estabeleceu-se à Cotovia, na freguesia de Santa Isabel. Quando morre, em 1774, deixa um órgão à Igreja do Loreto para que lhe rezem as missas pela $\operatorname{alma}^{24}$. Não são referidas as características do instrumento, mas uma vez que continua a ser mencionada a necessidade de se fazer um órgão condicente com o esplendor do templo novo, deveria ser um órgão pequeno.

${ }^{22}$ ANSL, Masso cartão II, F, doc. 2.

${ }^{23}$ ANSL, Masso cartão II, H, docs. 6, 7 e 8.

${ }^{24}$ ANTT, Registo Geral de Testamentos, Letra P, Livro 305, fl. 13. 
Entretanto, entre 1773 e 1774, a Junta do Loreto contrata Bento Fontanes para fazer a manutenção do órgão (Fig. 3). A preferência foi novamente para o organeiro da casa real. Terá pesado a qualidade desta oficina, uma das protagonistas do desenvolvimento da organaria em Portugal na 2. ${ }^{a}$ metade do século XVIII? Nesta altura, Leandro José da Cunha (1743dep. 1819), terceira geração dos Cunhas, assume o controlo da oficina familiar e passa a designá-la "fábrica" mas não há registos de ter trabalhado para o Loreto.

Para a inauguração do novo templo, em 1785, é contratado António Xavier Machado e Cerveira (1756-1828) para consertar e transportar o instrumento da sacristia (talvez o de Boni) para a igreja nova ${ }^{25}$ (Fig. 4). Este organeiro era natural de Aguim, perto de Coimbra, meio irmão do escultor Joaquim Machado de Castro e acabara de construir o grande órgão do novo templo da Basílica de Nossa Senhora dos Mártires. Cerveira foi talvez o único organeiro português a trabalhar em modelo pré-industrial e vem a ser organeiro da casa real.

\section{Proposta de um Devoto}

Não temos dúvidas que a comunidade italiana desejava ter um novo órgão, tecnicamente moderno e visualmente majestoso, para combinar com a arquitectura do novo templo. Para as cerimónias da inauguração, em 12 e 13 de Novembro de 1785, tiveram que alugar um instrumento. Em 1789 é registado em acta da Junta que um devoto propóe a construção de um novo órgão ${ }^{26}$.

$\mathrm{O}$ instrumento que se mandou fazer terá sido o que hoje se encontra no coro alto, identificado com a etiqueta da oficina de Machado e Cerveira e datado de 1791 (Fig. 5). Não encontramos porém, no arquivo, nem o contrato nem do-

${ }^{25}$ ANSL, Caixa IV/Organo, doc. 2.

${ }^{26}$ ANSL, Actas das Sessōes da Junta, Livro 2, p. 192. 
cumentos de despesa com a sua construção e assentamento. Ainda que o devoto ou outro mecenas tenham oferecido o órgão e o contrato não passasse pela igreja, seria normal que, pelo menos, as despesas de assentar o instrumento e os foles ficassem registadas na documentação da contabilidade da igreja. A única despesa que aparece associada a Machado e Cerveira é um recibo datado de 22 de Setembro de 1795, do pagamento pela afinação do órgão, mas sem qualquer informação mais específica sobre o instrumento.

Este órgão tem sido divulgado nas fontes como sendo construído por Joaquim António Peres Fontanes. Ernesto Vieira e Michel'angelo Lambertini, autores de artigos sobre a arte musical, no início do século XX, difundem a informação que tem sido repetida e que não encontra eco nem no arquivo histórico e, aparentemente, nem no órgão do coro alto - um restauro acabará com as dúvidas.

É Ernesto Vieira o primeiro a atribuir o órgão a Joaquim António Peres Fontanes, no Dicionário biográfico dos musicos portugueses, vol. I, p. 427. Michel'angelo Lambertini cita Vieira na sua monografia sobre o órgão ${ }^{27}$. Fontes recentes acrescentaram-lhe a data de 1782 . No arquivo da Igreja do Loreto, os únicos recibos da oficina Fontanes que encontramos são passados por Bento Fontanes Maqueira entre 1773 e 1774 e apenas para afinações e consertos.

\section{REPARAÇÕES E RECONSTRUÇŌES: SÉCULOS XIX E XX}

$\mathrm{Na} 1 .^{a}$ metade do século XIX a arte da organaria em Portugal decaiu. Durante as vagas das invasōes francesas (1807-1808, 1809 e 1810-1811), a par das dificuldades económicas ocasionadas pelo estado de guerra, inúmeros templos foram vandalizados e muitos órgãos de tubos destruídos. Associados à prática litúrgica, quando em 1834 é decretada a extinção das

${ }^{27}$ Michel'angelo Lambertini, "O Orgão", id., A Arte Musical, Ano II, 32, 30/Abr, Lisboa, Typ. do Annuario Comercial, 1900, p. 59. 
ordens religiosas, um grande número de instrumentos é deixado ao abandono. As igrejas paroquiais são quem vai continuar a utilizar os órgãos antigos até que ficam inutilizados.

Em 1819 o Loreto contrata António José Fontanes (17781828), filho de Bento, para fazer reparações no órgão ${ }^{28}$ (Fig. 6). Não deixa de ser curioso que não tenha sido chamado Machado e Cerveira, que o fez. Ainda mais que a oficina se localizava nas imediações da igreja, na Rua do Tesouro Velho (hoje António Maria Cardoso).

Entretanto, enquanto a arte da organaria entra em declínio, o negócio dos armazéns de música cresce. $\mathrm{Na} 2 .^{a}$ metade do século XIX este tipo de estabelecimento comercial abunda em Lisboa: C. A. Habel, Carciatto G., E. Meumann \& C.a, E. V. Wagner, Lambertini filho \& C. a, G. Fontana \& C.a, José de Figueiredo (antiga casa Ziegler), Lence \& Canongia Abraldes, Sassetti \& C. a, Augusto Neuparth, entre outros. ${ }^{29}$. Oferecem ao público uma larga gama de instrumentos estrangeiros, portáteis, mais cómodos e adaptados ao pragmatismo da época. Os tempos de pompa e fausto na celebração do culto tinham ficado para trás.

Do tempo antigo continua a funcionar em Lisboa um organeiro: Sebastiāo Gomes de Lemos (1788-1869), que trabalhou na fábrica de Machado e Cerveira e que, por morte deste, continuou no lugar de responsável pelos órgãos de Mafra. Em 1865 tinha a loja na Rua de Jesus, n. ${ }^{\circ}$ s 9 e 11, freguesia das Mercês, em Lisboa ${ }^{30}$.

\section{Adolph J. Mellert, de Hamburgo}

Em 1879 a Junta administrativa do Loreto contrata Adolph J. Mellert, de Spaichingen, Hamburgo. São aprovados

\footnotetext{
${ }^{28}$ ANSL, Masso cartão II, H, doc. 13 (1819/12/04).

${ }^{29}$ Zacharias de Vilhena Barbosa, Almanak Industrial, Comercial e Profissional de Lisboa para o ano de 1865..., Lisboa, Imprensa Nacional, 1865, pp. 81-84.

${ }^{30}$ Id., ib., p. 398.
} 
$800 \$ 000$ reis para reparar o órgão. Este organeiro era conhecido entre nós. Mellert terá tentado captar outros trabalhos em Lisboa. Exemplo disso é um projecto que apresentou para a recuperação dos dois órgãos do Mosteiro dos Jerónimos, hoje desaparecidos ${ }^{31}$.

O órgão construído por Machado e Cerveira em 1791 é bastante mexido nesta reparação, que decorre entre 1879 e 1881. Os tubos vão a reparar na Alemanha. Os documentos do arquivo do Loreto registam cinco remessas de tubos vindos de Hamburgo mas não se percebe se foram aproveitados os tubos antigos ou se fizeram tubos novos.

João A. P. Sampaio, fornecedor do estado

A última grande reparação foi feita entre 1933 e 1935 pela Casa Sampaio. Os Sampaio tinham a loja na Travessa do Monte, n. ${ }^{\text { }} 7$, em Lisboa, reparando tanto órgãos como pianos e o seu director técnico era o engenheiro J. Ramos Sampaio $^{32}$ (fig. 7).

Estamos no início do Estado Novo. A aposta no ensino técnico e industrial e sobretudo no fazer as coisas com a prata da casa e a baixo custo é incentivado pelo estado. Para a arte da organaria é a era dos técnicos e engenheiros.

Os organeiros portugueses tinham-se praticamente extinguido na 2. ${ }^{a}$ metade do século XIX sem que chegassem a emergir fábricas com sistemas modernos de construção. A forte presença das marcas estrangeiras no mercado português acabou com a indústria local, mas não apagou a memória de que esta arte teve bons artífices entre nós. Para a época, a Casa Sampaio foi um exemplo do reacender do brio e do orgulho num trabalho nacional competente.

Vale a pena transcrever aqui o texto do interior da brochura feita para a inauguração do órgão recuperado, em 1934, porque nos dá elementos sobre as características do órgão e simultaneamente sobre a filosofia da intervenção:

\footnotetext{
${ }^{31}$ Sousa Viterbo, Subsidios, Coimbra, 1932, pp. 372-373.

${ }^{32}$ ANSL, Maço 34, doc. sem n. ${ }^{\circ}(1934 / 12 / 27)$.
} 


\section{DESCRIÇÃO E ESPECIFICAÇÃO}

Êste órgão foi reconstruído quási exclusivamente com os tubos dos velhos registos completados com tubos novos, dos quais, alguns de nosso fabrico próprio.

A transmissão mecânica foi em grande parte renovada com o fim de tornar os teclados o menos possível pesados, o que se conseguiu absolutamente.

A caixa exterior foi cuidadosamente restaurada, sendo a consola inteiramente folheada e encerada, em substituição da imprópria pintura branca a óleo.

Muito outro material foi completamente renovado dentro dos limites de uma reconstrução económica.

O órgão, situado à direita do Côro, ocupa um volume de 50 m3, não incluindo os foles, sendo êste volume aproveitado ao máximo, a ponto de tornar as visitas interiores bastante difíceis.

Funcionara pela última vez em 1886, tendo permanecido 48 anos num estado de inutilização absoluta.

Possui 1.700 tubos distribuídos por 32 registos (...).

O ventilador eléctrico foi fornecido pela casa Marelli. Ficamos também a saber que o órgão estava mudo desde 1886, cinco anos após Adolph J. Mellert ter concluído a reparação.

Século XX: encomenda a Carlo Vigezzi Bossi (18581927), DE Turim, ITÁliA

Entre os trabalhos de reparação e restauro efectuados por Meller em 1879-1881 e pela Casa Sampaio em 1933-1934, a Junta do Loreto fez uma tentativa de encomendar um órgão novo. Aconselha-se com um especialista da Academia de Santa Cecília, em Roma e o organeiro sugerido é Carlo Vigezzi Bossi, que os italianos apelidam de Cavaillé-Coll italiano.

Em 1914 assinaram contrato e deram 6.000 liras em avanço. O órgão seria entregue em 27 de Julho de 1915. Em 1916 são informados que a empresa faliu e que os credores 
seriam ressarcidos usando $7 \%$ da verba da liquidação. Carlo Vigezzi Bossi entrara em falência no decorrer da $1{ }^{a}$ Grande Guerra. A Junta tinha reservado 20.000 liras para o novo órgão mas decide não procurar outro organeiro. Resolve antes usá-lo na ajuda de vítimas da guerra.

\section{BREVES PALAVRAS FINAIS}

O insucesso da encomenda do órgão a Vigezzi talvez tenha sido a sobrevivência do órgão do coro alto, testemunho técnico de uma época áurea da organaria em Portugal e da escolha feita pela comunidade italiana para a prática musical na sua igreja.

Sobre a qualidade dos organeiros em Lisboa neste período, Adrien Balbi, um geógrafo veneziano que entendia a geografia também como uma descrição de todos os recursos existentes num dado lugar, quando esteve em Lisboa, entre 1819 e 1820, escreve a propósito dos organeiros locais: Les facteurs d'orgues ne sont qu'en petit nombre, mais ils travallent fort bien ${ }^{33}$.

Seria interessante estudar a prática musical antiga da Igreja do Loreto e depois fazê-la soar no templo, no órgão antigo, contemporâneo dessa prática. Haverá melhor maneira de celebrar a antiguidade e identidade do que a preservação dos tesouros que nos são legados pelos antepassados?

\footnotetext{
${ }^{33}$ Adrien Balbi, Essai Statistique sur le Royaume de Portugal et d'Algarve, Ed. Imprensa Nacional Casa da Moeda e Faculdade de Economia da Universidade de Coimbra, 2004, Tomo I, p. 461. Tradução livre da autora: "Os construtores de órgãos são poucos mas trabalham muito bem”.
} 


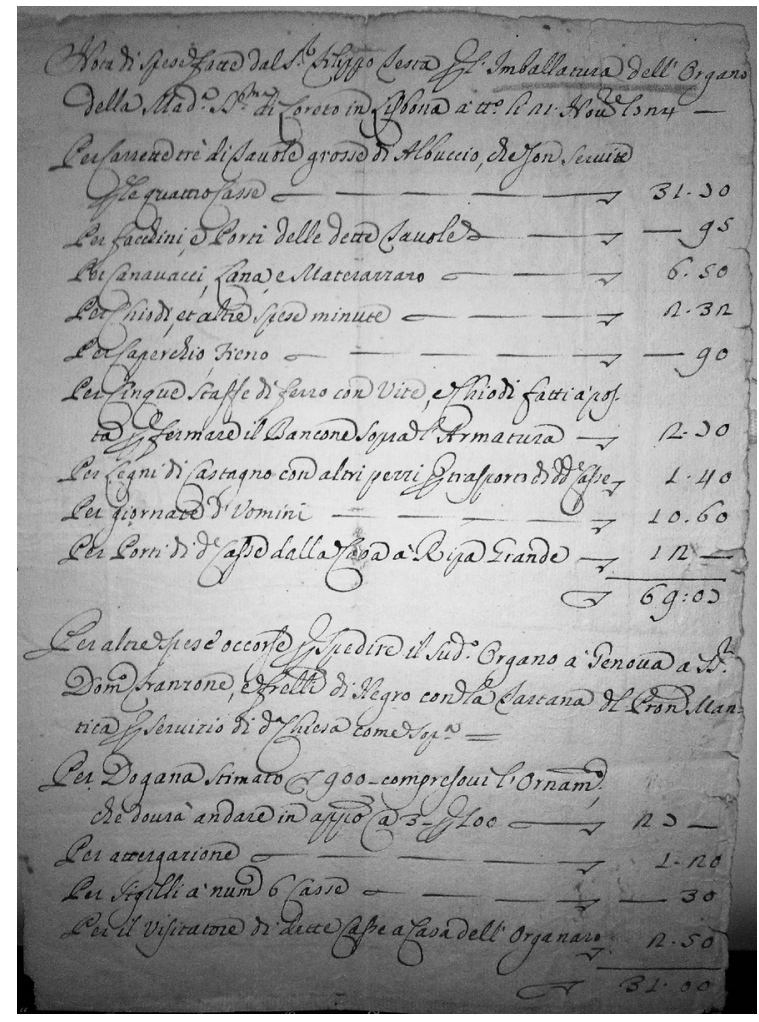

Fig. 1

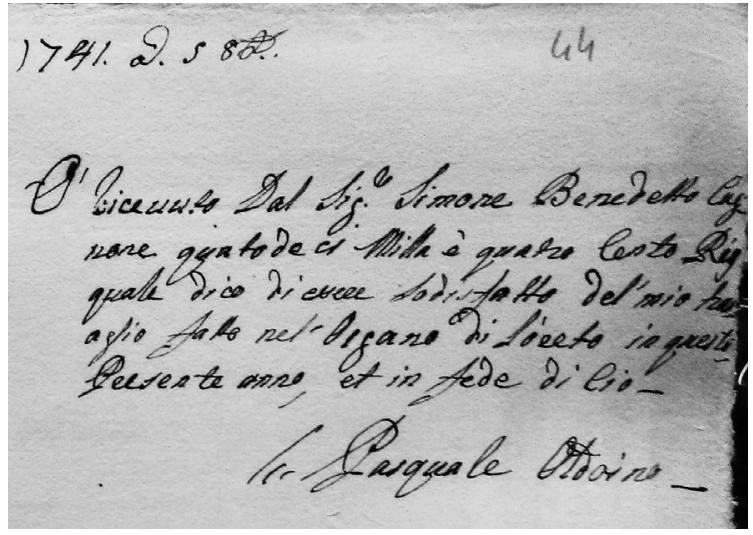

Fig. 2 
II8 Ana Paula Tudela

6)

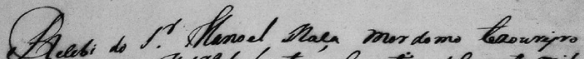

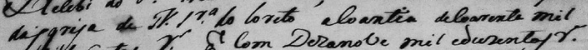

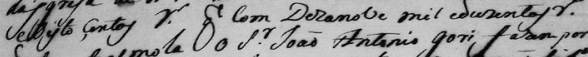

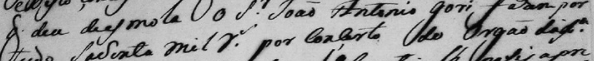

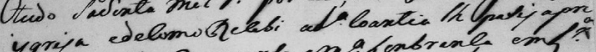

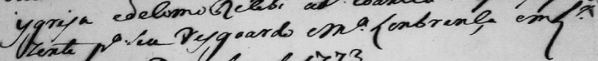
as 21 de Destabro dir73

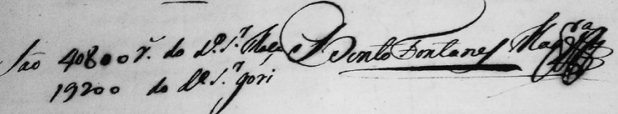

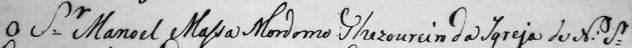

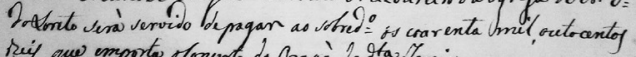

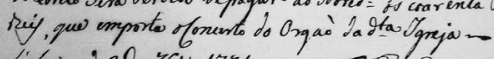

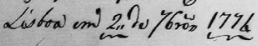

ad PLod80.
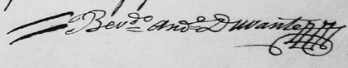

Fig. 3
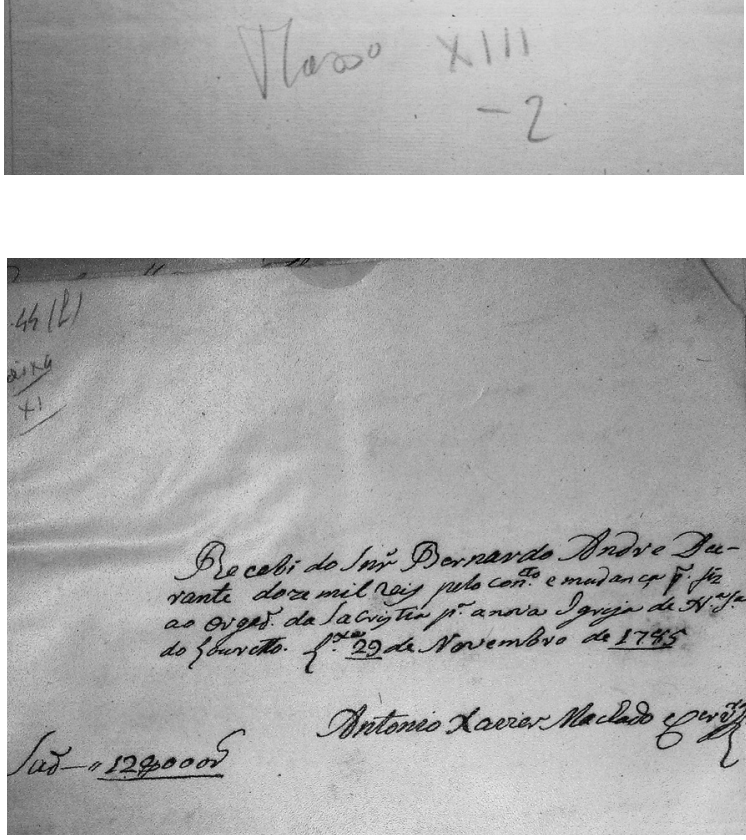

Fig. 4 
Órgão de tubos da Igreja de Nossa Senhora do Loreto II9

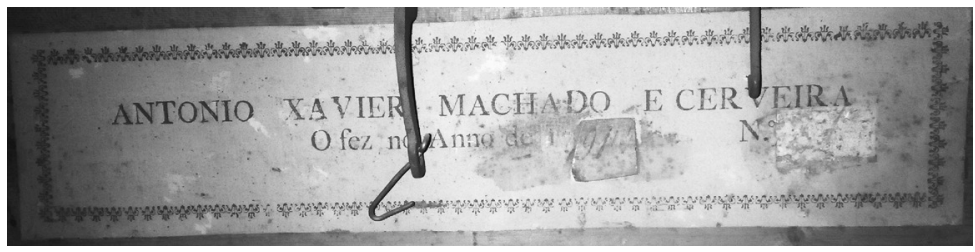

Fig. 5

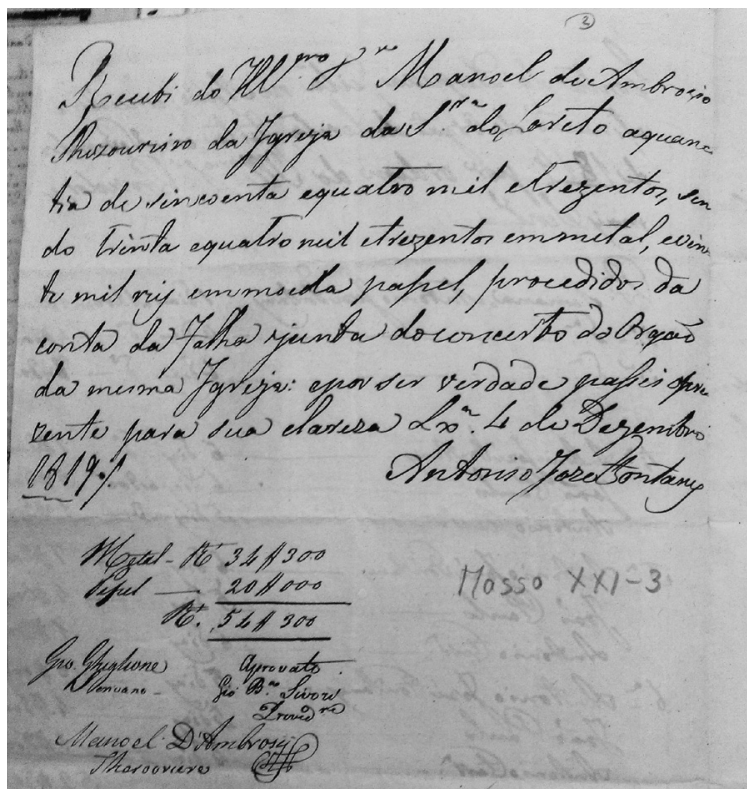

Fig. 6 